\title{
Preferred partitioning: the influence of coalescents on the build-up of mechanical properties in acrylic core-shell particles (I)
}

\author{
Bas Lohmeijer, Roelof Balk, Roland Baumstark
}

(C) The Author(s) 2012. This article is published with open access at Springerlink.com

\begin{abstract}
The partitioning of three coalescents of different polarity in different phases of multiphase acrylic particles was studied to provide a rationale for obtaining the desired performance of binders for wood coatings in terms of the ideal balance between hardness development, blocking resistance, and blushing resistance. Minimum film formation temperature- and aqueous differential scanning calorimetry-measurements on the hard phase polymer by itself showed the different extents to which both hydroplasticization and plasticization by the coalescent occur. Dynamic mechanical thermal analysis was subsequently used to visualize wet- $T_{\mathrm{g}}$ effects of three different coalescents in the hard and soft polymer phase of these multiphase acrylic particles. The results have important consequences for the formulation of such binders in applications for exterior wood coatings and coatings in general.
\end{abstract}

Keywords Emulsion polymerization, Straight acrylic dispersion, Film formation, Coalescent, Dynamic mechanical analysis, Wood coatings, Mechanical properties

\section{Introduction}

The quality and durability of waterborne wood coatings systems depend to a large extent on the degree of film formation of the polymer latex. ${ }^{1}$ For example, in exterior wood coatings, excellent early hot blocking resistance is a primary requirement of the coatings manufacturer, as it allows good stackability of the finished product and an increase in production efficiency.

B. Lohmeijer ( $\square)$, R. Balk, R. Baumstark

BASF SE, Carl-Boschstrasse 38, 67056 Ludwigshafen,

Germany

e-mail: bas.lohmeijer@basf.com
Moreover, other important coatings properties such as early blushing resistance and hardness development are profoundly influenced by the degree of completion of the film formation process. By reducing the drying times (also at higher temperatures) the binder is still expected to deliver defect-free films with excellent film mechanics and durability. Knowledge about how properties such as early hot blocking and early blushing resistance depend on the completeness of the film formation process allows for optimal selection and use of film forming aids on the one hand. On the other hand, it also provides an important design parameter for (improving) the polymer latex and moving from empiry to strategy. This article aims to demonstrate the build-up of mechanical properties and its impact on application-relevant properties of novel (hydro)plasticized polymer dispersions.

The basic model of concurrent steps of latex concentration, particle packing, particle deformation, coalescence, and polymer interdiffusion has been extensively reviewed, most notably for single-phase polymer dispersions. ${ }^{2-4} \mathrm{~A}$ number of methods are available to probe the degree of film formation, for example by diffusion wave spectroscopy,${ }^{5}$ magnetic resonance imaging (MRI)-profiling, ${ }^{6}$ fluorescence resonance energy transfer (FRET)-techniques, ${ }^{7,8}$ microscopic techniques, ${ }^{9}$ and neutron scattering. ${ }^{10}$ The drawback of all these techniques is that they do not provide information on the development of the mechanical properties of the coating film, which are crucial for the performance. The interdiffusion stage is of course the most important stage for the build-up of mechanical properties. In many cases coalescents are still required to enable good interdiffusion of the polymer chains by lowering the minimum film formation temperature (MFFT) through temporary plasticization of the polymer, even if the current trend is clearly towards low or no volatile organic compounds (VOCs). ${ }^{11}$ In addition, even under non-favorable film 
formation conditions (e.g., low temperature, high humidity, and in thick layer application) the coating system is still expected to deliver the desired performance. ${ }^{12}$ Also here coalescents are often used to mitigate such non-favorable conditions. A clever design concept of the binder, e.g., applying multiphase particle technologies in combination with careful control over the coalescent compatibility of the different phases, can make a further reduction of the coalescent level feasible. This creates favorable partitioning of the coalescent at all stages of the film formation and enables further reduction in the coalescent level, as described recently in polymer dispersion blends of polyurethanes and polyacrylics. ${ }^{13}$ Most elegant is the use of water as "coalescent," also known as hydroplasticization. ${ }^{14,15}$ Unfortunately in that case, the required high polarity of the polymer leads to water sensitivity of the coating. Being an active area of research, several recent models provide the calculation of the hydroplasticized glass transition temperature $\left(T_{\mathrm{g}}\right)$ of a polymer, ${ }^{16}$ whereas other work has focused on the plasticization by different coalescents in relation to the drying process. ${ }^{17}$ Nonetheless, also here the development of the mechanical properties is not taken into account.

Multiphase particles combining hard high $T_{\mathrm{g}}$ and soft low $T_{\mathrm{g}}$ phases are typically used to fulfill the blocking resistance requirement. ${ }^{18}$ The hard phase is in most cases more hydrophilic than the soft phase and is thermodynamically driven to the outside of the particles. The preparation of such particles has been extensively reviewed and a multitude of morphologies can be designed by varying both product and process parameters ${ }^{19}$; here we will focus on core-shell particles, where a hydrophobic soft phase is enveloped by a hydrophilic hard phase. The hydrophilic phase in this study has been prepared by the so-called rheology controlled (RC) technique, ${ }^{20,21}$ where a low molecular weight hydrophilic polymer is used for the emulsion polymerization of a more hydrophobic soft phase. To reduce the water sensitivity of the final films, the binder contains a self-crosslinking mechanism.

The basic film formation process of such particles is schematically represented in Fig. 1a and an atomic force microscopy (AFM)-image is shown in Fig. 1b, which shows to a good approximation a continuous hard phase that envelops the soft phase(s).

In this article, we study the effect of different coalescents on the film formation efficiency of this kind of new generation polymer latex. For this purpose we have investigated the MFFT and the hydroplasticized $T_{\mathrm{g}}$ by aqueous differential scanning calorimetry (DSC) of the hydrophilic hard phase by itself, the development of the pendulum hardness of the polymer films from dispersions utilizing such a hydrophilic hard phase and the time-dependent mechanical properties of these films by dynamic mechanical thermal analysis (DMTA)-measurements, with and without coalescent.

\section{Experimental}

The polymer in this study has been prepared by a proprietary process. The polymer dispersion is a very fine-sized, multiphase, self-crosslinking all-acrylic. The self-crosslinking reactions occur after film formation. Solvents used were: Lusolvan BDG (BASF SE), Solvenon DPM (BASF SE), and Texanol (Eastman Chemical). BDG stands for butyldiglycol and is also known as butyl carbitol or by its systematic name 2-(2butoxyethoxy)ethanol, DPM is the abbreviation for dipropyleneglycol methyl ether or 2-(2-methoxypropoxy)propan-1-ol. Texanol is 2,2,4-trimethyl-1,3-pentandiol-monoisobutyrate. Table 2 (vide infra) gives some (a)
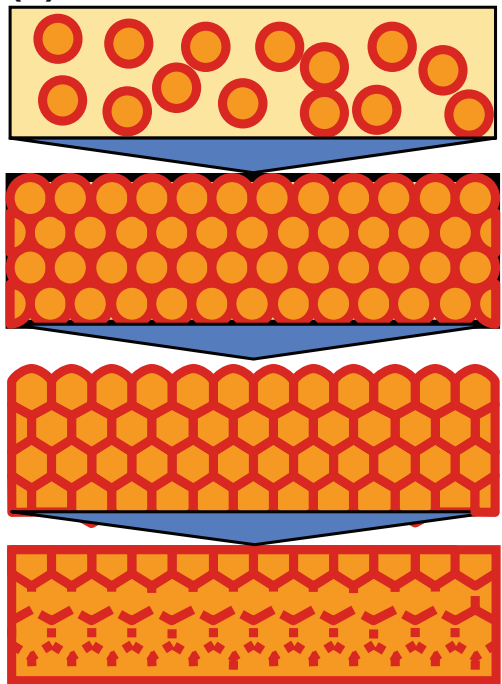

(b)

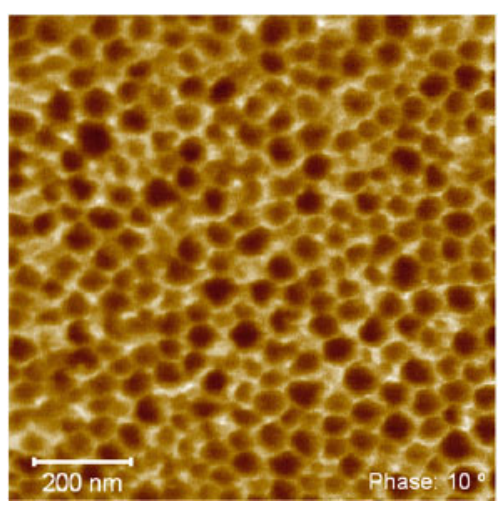

\section{Coalescence,}

Aqueous Latex

Evaporation and

Concentration

Deformation

and

Crosslinking

Interdiffusion and Crosslinking

Fig. 1: (a) Schematic representation of latex film formation of a core-shell polymer dispersion (left) and (b) the corresponding AFM-phase image of such a dried polymer latex film (right: hard phase corresponds to bright color, soft phase is dark) 
more information on these coalescents. MFFT measurements were carried out on a Coesfeld Thermostair according to DIN ISO 2115. Aqueous DSC was performed with a TA Q-2000 with a heating rate of $10^{\circ} \mathrm{C} / \mathrm{min}$ and scanning from 5 to $140^{\circ} \mathrm{C}$ on the hydrophilic hard phase prepared in water using sealable sample containers with approximately $40-50 \mathrm{mg}$ of sample. The wet $T_{\mathrm{g}}$ was taken from the first heating run using the Perkin Elmer analysis software. Reliable, reproducible data could be obtained from ca. $40^{\circ} \mathrm{C}$ onwards. AFM measurement was done on a Dimension D5 Bruker (Veeco) microscope. The cross section was prepared by an ultra-microtome under cryogenic conditions and measured at room temperature (RT) afterwards. DMTA was performed on films with a thickness of ca. $500 \mu \mathrm{m}$ at $1 \mathrm{~Hz}$ and $4^{\circ} \mathrm{C} / \mathrm{min}$ using a TA Instruments DMTA V constant strain rheometer. König pendulum hardness was measured after 1, 3, and 7 days drying at RT of films of $100 \mu \mathrm{m}$ wet thickness cast on glass using a doctor blade after DIN EN ISO 1522. The values in Fig. 2 are an average of three measurements. Blushing experiments were conducted by casting a $300 \mu \mathrm{m}$ wet film on glass on a black background. The film was dried for either $24 \mathrm{~h}$ or 7 days at RT and was subsequently brought in contact with deionized water for the specified amount of time $(1,2$, and $4 \mathrm{~h})$. Evaluation was by visual inspection and/or photographic imaging. Blocking resistance was determined by casting a $300 \mu \mathrm{m}$ wet film on two individual predried planed pine panels. After drying for $24 \mathrm{~h}$ or 7 days at RT, the individual samples are stacked face-to-face and a pressure corresponding to $400 \mathrm{~g} / \mathrm{cm}^{2}$ is applied. The stacked samples are immediately placed in a $50^{\circ} \mathrm{C}$ oven, from which they are removed after $24 \mathrm{~h}$. The face-to-face samples are then released from each other after cooling to RT and the

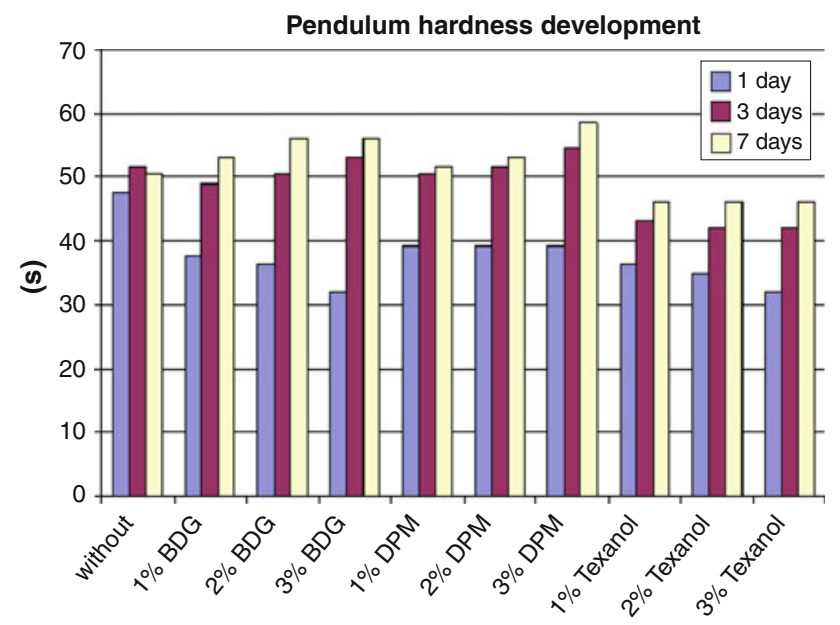

Fig. 2: Development of the pendulum hardness after König of a polymer binder without and at 1, 2, and $3 \mathrm{wt} \%$ levels of BDG, DPM, and Texanol, respectively force required for separation is evaluated together with the surface damage.

\section{Results and discussion}

As mentioned before, a hydrophilic phase is more strongly plasticized by water. This has been corroborated by MFFT- and aqueous DSC-measurements of the hydrophilic hard phase by itself (i.e., before polymerization of the soft phase) in comparison with DSC-measurements of the dried protective colloid, in the absence of the postfilm formation crosslinking agents. Calculating the wet and dry $T_{\mathrm{g}}$ after the model of Tsavalas ${ }^{16}$ gives values of 86 and $84^{\circ} \mathrm{C}$ for the dry $T_{\mathrm{g}}$ at $\mathrm{pH}<3$ and $\mathrm{pH}>10$, respectively, and values of 62 and $54^{\circ} \mathrm{C}$ for the wet $T_{\mathrm{g}}$ at $\mathrm{pH}<3$ and $\mathrm{pH}>10$, respectively. By DSC the dry $T_{\mathrm{g}}$ of the protective colloid was measured at $84^{\circ} \mathrm{C}$, which is in excellent agreement with the model. The first entry in Table 1 shows that by MFFT-measurements we obtain a wet $T_{\mathrm{g}}$ of 74 and $72^{\circ} \mathrm{C}$ at the respective pHs. Interestingly enough, by aqueous DSC we obtain $T_{\mathrm{g}}$ values of 63 and $55^{\circ} \mathrm{C}$, which are once again in excellent agreement with the model of Tsavalas.

We can conclude that there is a reduction of the MFFT by hydroplasticization, and that theoretically the model of Tsavalas works quite well for predicting the hydroplasticized $T_{\mathrm{g}}$. Nonetheless, there remains a discrepancy between the measured wet $T_{\mathrm{g}}$ by aqueous DSC and the measured MFFT, which can be explained by the faster evaporation of water on the MFFT-bar. This results in a shift of the MFFT to higher temperatures than would be expected based on the wet $T_{\mathrm{g}}$. It also has to be kept in mind that film thickness can play a role on the MFFT-bar. From an application point of view, however, the MFFT-bar is the better tool for probing good film formation under practical conditions-one just has to be careful with the interpretation.

The efficacy of the coalescent on reducing the MFFT of the hydrophilic hard phase has been studied by adding increasing amounts of different coalescents and measuring both the MFFT and the wet $T_{\mathrm{g}}$ by aqueous DSC (see Tables 1, 2,3). Texanol, DPM, and BDG all show a significant reduction of the MFFT (Table 1). BDG turns out to be most effective in reducing the MFFT at both loadings; both Texanol and DPM are less effective. At higher $\mathrm{pH}$ the hydrophilic coalescents BDG and DPM are more effective, which is reflected in a further decrease of the MFFT and in agreement with the more hydrophilic nature of the hard phase at this $\mathrm{pH}$ due to the deprotonation of carboxylic acid groups. By aqueous DSC the results seem at first counterintuitive, as DPM and BDG seem less effective than Texanol in reducing the wet $T_{\mathrm{g}}$ at comparable loading. Based on the water solubilities (Table 2), however, the much stronger partitioning of DPM and BDG over the aqueous phase leads to less coalescent being available to plasticize the polymer. 
Table 1: Effect of water, pH, and two different coalescent levels on the MFFT of the hydrophilic hard phase

\begin{tabular}{|c|c|c|c|c|c|c|}
\hline \multirow[t]{2}{*}{ Coalescent } & \multicolumn{2}{|c|}{$0 \%$} & \multicolumn{2}{|c|}{$3 \%$} & \multicolumn{2}{|c|}{$6 \%$} \\
\hline & $\mathrm{pH} 3$ & $\mathrm{pH} 8$ & $\mathrm{pH} 3$ & pH 8 & pH 3 & $\mathrm{pH} 8$ \\
\hline None & $74^{\circ} \mathrm{C}$ & $72^{\circ} \mathrm{C}$ & - & - & - & - \\
\hline DPM & - & - & $50^{\circ} \mathrm{C}$ & $41^{\circ} \mathrm{C}$ & $21^{\circ} \mathrm{C}$ & $20^{\circ} \mathrm{C}$ \\
\hline BDG & - & - & $43^{\circ} \mathrm{C}$ & $31^{\circ} \mathrm{C}$ & * & $7^{\circ} \mathrm{C}$ \\
\hline Texanol & - & - & $46^{\circ} \mathrm{C}$ & $42^{\circ} \mathrm{C}$ & $17^{\circ} \mathrm{C}$ & $18^{\circ} \mathrm{C}$ \\
\hline
\end{tabular}

* Could not be measured due to gelation

Table 2: Characteristics of the coalescents under use in this study ${ }^{22-24}$

\begin{tabular}{lcccc} 
Coalescent & $\begin{array}{c}\text { Boiling } \\
\text { point } \\
\left({ }^{\circ} \mathrm{C}\right)\end{array}$ & $\begin{array}{c}\text { Relative } \\
\text { evaporation } \\
\text { rate vs BuAc }\end{array}$ & $\begin{array}{c}\text { Relative } \\
\text { evaporation } \\
\text { rate vs ether }\end{array}$ & $\begin{array}{c}\text { Water } \\
\text { solubility } \\
(\mathrm{g} / \mathrm{L})\end{array}$ \\
\hline DPM & 190 & 2 & 400 & $\infty$ \\
BDG & 231 & 0.4 & 3750 & $\infty$ \\
Texanol & 254 & 0.2 & 6051 & 0.858 \\
\hline
\end{tabular}

Table 3: Effect of water, $\mathrm{pH}$, and 3\% coalescent levels on the wet $T_{\mathrm{g}}$ of the hydrophilic hard phase, as measured by aqueous DSC

\begin{tabular}{|c|c|c|c|}
\hline \multirow[t]{2}{*}{ Coalescent } & \multicolumn{2}{|c|}{$0 \%$} & \multirow{2}{*}{$\begin{array}{c}3 \% \\
\mathrm{pH} 8\end{array}$} \\
\hline & $\mathrm{pH} 3$ & $\mathrm{pH} 8$ & \\
\hline None & $63^{\circ} \mathrm{C}$ & $55^{\circ} \mathrm{C}$ & - \\
\hline DPM & - & - & $57^{\circ} \mathrm{C}$ \\
\hline BDG & - & - & $54^{\circ} \mathrm{C}$ \\
\hline Texanol & - & - & $<40^{\circ} \mathrm{C}^{\star}$ \\
\hline
\end{tabular}

* Could not be measured reliably due to baseline instabilities. Nonetheless, at $2 \%$ Texanol the wet $T_{\mathrm{g}}$ already drops to $46^{\circ} \mathrm{C}$, much lower than the reported values for $3 \%$ of DPM and BDG

The lower water solubility of Texanol $(858 \mathrm{mg} / \mathrm{L})^{24}$ forces it into the polymer and helps decrease the wet $T_{\mathrm{g}}$ more effectively at equal coalescent loading. Taking once again into account that on the MFFT-bar water will evaporate faster than the coalescent, the apparent concentration of coalescent is higher and therefore the MFFT will drop. This is also corroborated by MFFTmeasurements at even higher levels of coalescent $(6 \%)$, where Texanol seems to become as effective as DPM. This can be explained by the fact that DPM has in comparison to Texanol a much higher evaporation rate.

These experiments have shown that commonly applied coalescents can be used to facilitate the film formation of the hydrophilic hard phase. As expected, hydrophilic cosolvents such as BDG are more effective than hydrophobic ones such as Texanol, but only after sufficient evaporation of water due to the partitioning effects in combination with the water solubilities. For effective plasticization of the encapsulated hydrophobic soft phase depends on the changing partitioning of the coalescent between the aqueous phase, the hydrophilic hard phase, and the hydrophobic soft phase as a function of the water loss during the drying process. Therefore, the above-mentioned results by themselves do not suffice for selecting the right coalescent (package) for optimum film formation. Finally, partitioning can be expected to have a large impact on the final materials properties.

The development of the mechanical properties of the binder film (containing the hydrophilic hard phase as well as a film-forming soft phase) has been studied by simple pendulum hardness measurements after König of the binder film after different drying times. To the polymer dispersion, 1,2 , and $3 \mathrm{wt} \%$ of DPM, BDG, and Texanol were added and after 24,72 , and $168 \mathrm{~h}$ the pendulum hardness was measured. The results are shown in Fig. 2.

Figure 2 shows that the pendulum hardness of the film without any coalescents does not increase much after 1 day of drying; hence, the film is considered dry. All of the tested coalescents lead to significantly reduced pendulum hardness after 1 day drying, indicating that they have not fully evaporated-even if the water has already left the film. Texanol, the coalescent with the highest boiling point and lowest evaporation rate, leads to a binder film that does not reach the pendulum hardness of the coalescent-free film-even after 7 days. Interestingly enough, both BDG and DPM, especially at the higher loadings of 2 and 3\%, show a pendulum hardness above that of the coalescent-free binder film. Based on the results in Table 1 it should be evident that the higher pendulum hardness may be explained by the enhanced film formation of the hard phase and therefore a potentially more effective postfilm formation crosslinking. However, these measurements still give no indication on how the coalescent partitions between the soft and hard phases.

To understand the partitioning of the coalescent over the hard and the soft phase we turned to DMTAmeasurements. Even if the dry film thickness for such measurements is with ca. 0.4-0.6 mm much higher than for coatings systems in practice-and therefore negatively impacting the drying times-the technique 
provides a qualitative insight into the development of the mechanical properties over the course of film formation and coalescent evaporation. It also provides a quantitative means for probing the individual effect of the coalescent on the different phases.

It must be kept in mind, that during the measurements especially at temperatures above RT the samples will start losing residual coalescent $\left(\mathrm{H}_{2} \mathrm{O}\right.$, Texanol, BDG, or DPM) and also annealing. These effects will be greater the higher the temperature and the lower the boiling point of the coalescent, which means that some error in the curves is present in the region above RT increasing towards higher temperatures. However, multiple repetition of the experiments showed excellent correlation and statistics. Therefore, we are confident that the observed differences between the various drying times and used coalescents are significant.

Figure 3 shows DMTA-measurements of a drying film without coalescents after several time intervals. The $E^{\prime}$-modulus in the range between the two glass transition temperatures increases up to a maximum, as film formation proceeds. It can clearly be seen that the shoulder of the tan delta peak of the hard phase, observed at about $50^{\circ} \mathrm{C}$, shifts to higher temperatures and finally disappears. This may be due to three effects: prior to drying because of residual water mainly present in the hard phase plasticizing it, relaxational effects due to the fact that the morphology is at least partly kinetically determined and develops slowly to a more thermodynamically stable configuration, and postfilm formation crosslinking of the hard phase taking place in the course of the drying process. Both the shape and the position of the tan delta peak of the soft phase stay fairly constant-indicating that the morphology hardly changes during the drying and annealing time. Finally, drying the film for more than 1 week at $40^{\circ} \mathrm{C}$ under vacuum gives within experimental error the same DMTA-curve as after 11 weeks drying at RT.

The addition of $3 \mathrm{wt} \%$ of Texanol and its effect on the development of the soft and hard phase during the drying process is shown in Fig. 4. Texanol reduces the $T_{\mathrm{g}}$ of both the soft phase (from ca. -20 to $-30^{\circ} \mathrm{C}$ ) as well as of the hard phase (from ca. 110 to $100^{\circ} \mathrm{C}$ ) with a shoulder in the tan delta-curve starting at ca. $40^{\circ} \mathrm{C}$ after the shortest drying time. After 10 days of drying the peak maxima in the tan delta-curve shift stronger for the soft phase than for the hard phase. The peak for the hard phase still displays a large shoulder. However, after 7 weeks of drying the tan delta peak of the hard phase has shifted further to higher temperatures than the tan delta peak of the soft phase. After 11 weeks of drying at RT the DMTA-curve is still not identical to the DMTA-curve after drying for 1 week at $40^{\circ} \mathrm{C}$, indicating that residual Texanol is still present in both phases.

The addition of $3 \mathrm{wt} \%$ of BDG and its effect on the development of the soft and hard phase during the drying process is shown in Fig. 5. BDG also reduces the $T_{\mathrm{g}}$ of both phases (from ca. -20 to $-30^{\circ} \mathrm{C}$ and from ca. 110 to $90^{\circ} \mathrm{C}$ for the soft and hard phase, respectively). The shoulder in the tan delta-curve starts at ca. $30^{\circ} \mathrm{C}$ Clearly, BDG has a much more pronounced effect on plasticizing the hard phase than Texanol.

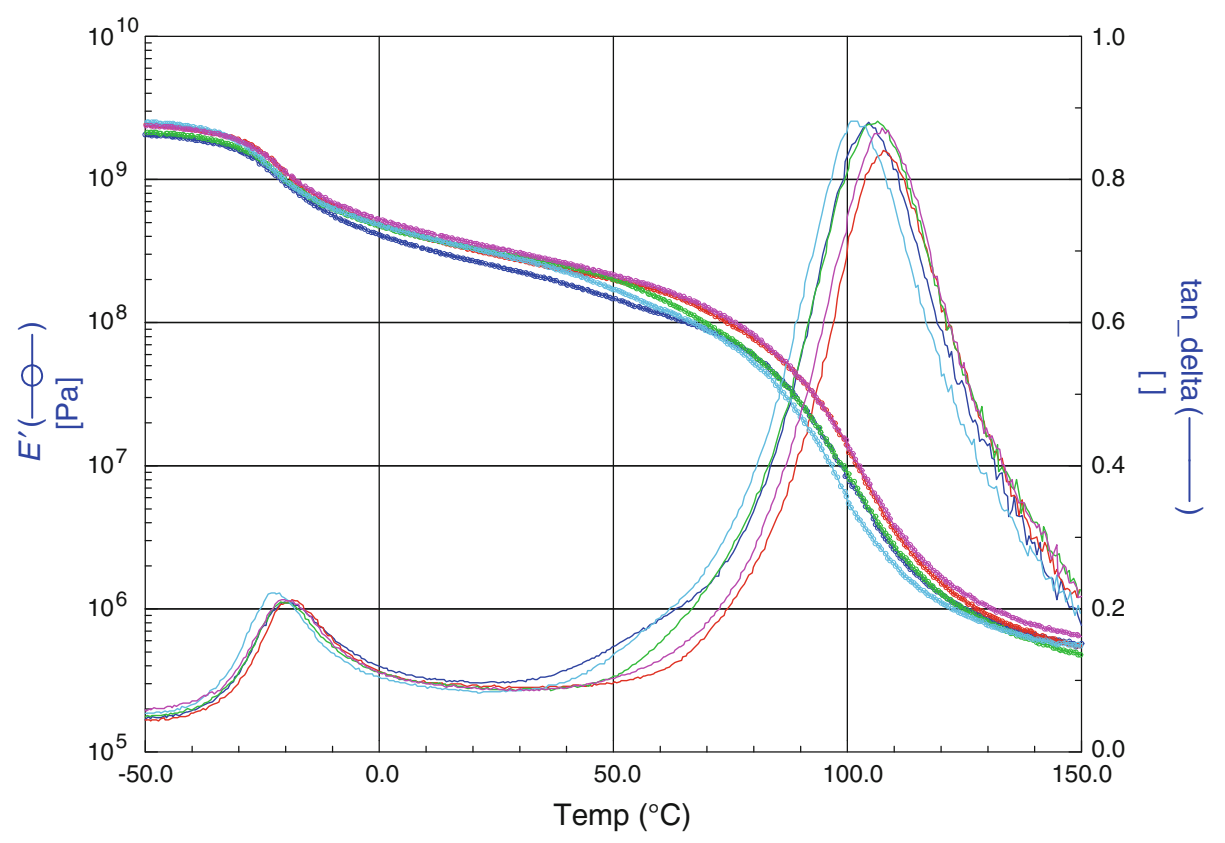

Fig. 3: $E^{\prime}$-modulus- and tan delta-curves of the binder after different periods of drying time without using any coalescent. Blue lines: after 3 days RT, light blue lines: after 11 days RT, green lines: after 7 weeks RT, violet lines: after 11 weeks RT, red lines: after 3 days $\mathrm{RT}+11$ days at $40^{\circ} \mathrm{C}$ (Color figure online) 


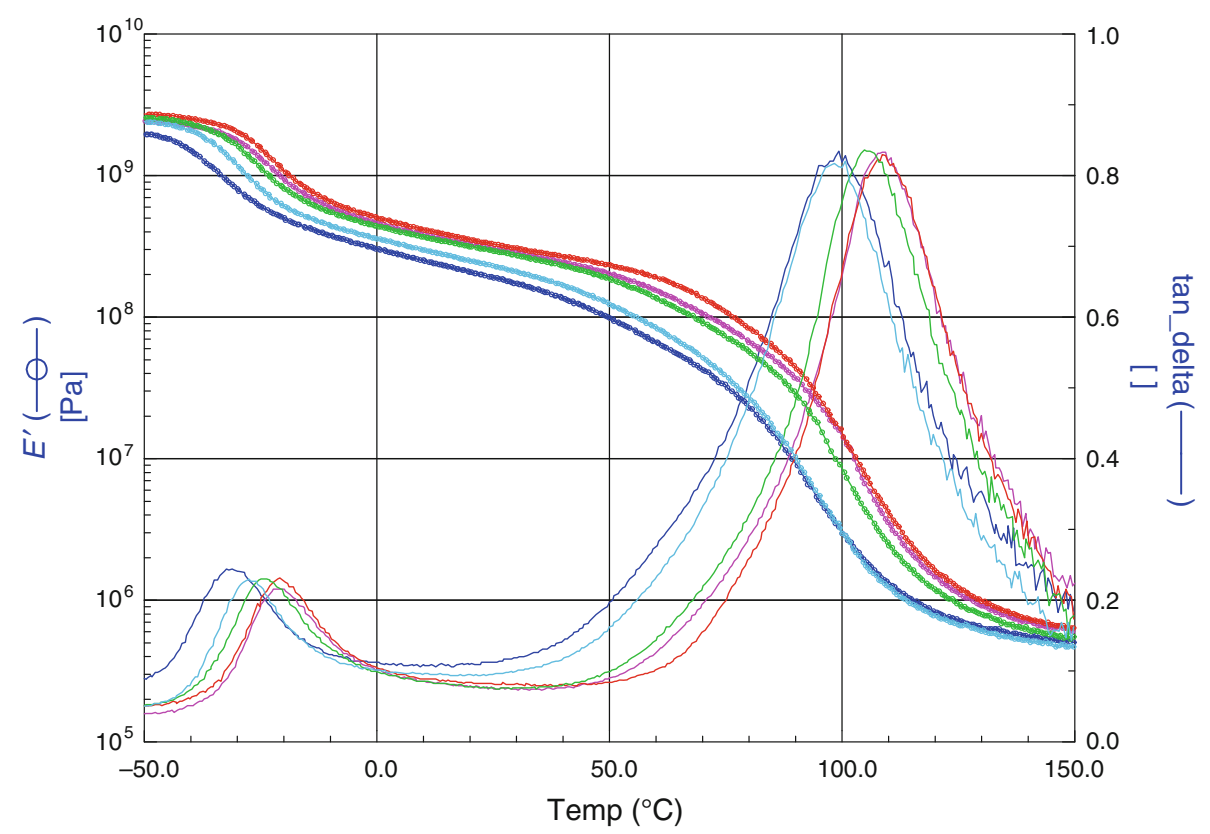

Fig. 4: $E^{\prime}$-modulus- and tan delta-curves of the binder after different periods of drying time by the addition of 3 wt\% Texanol. Blue lines: after 3 days RT, light blue lines: after 10 days RT, green lines: after 7 weeks RT, violet lines: after 11 weeks RT, red lines: after 3 days $\mathrm{RT}+11$ days at $40^{\circ} \mathrm{C}$ (Color figure online)

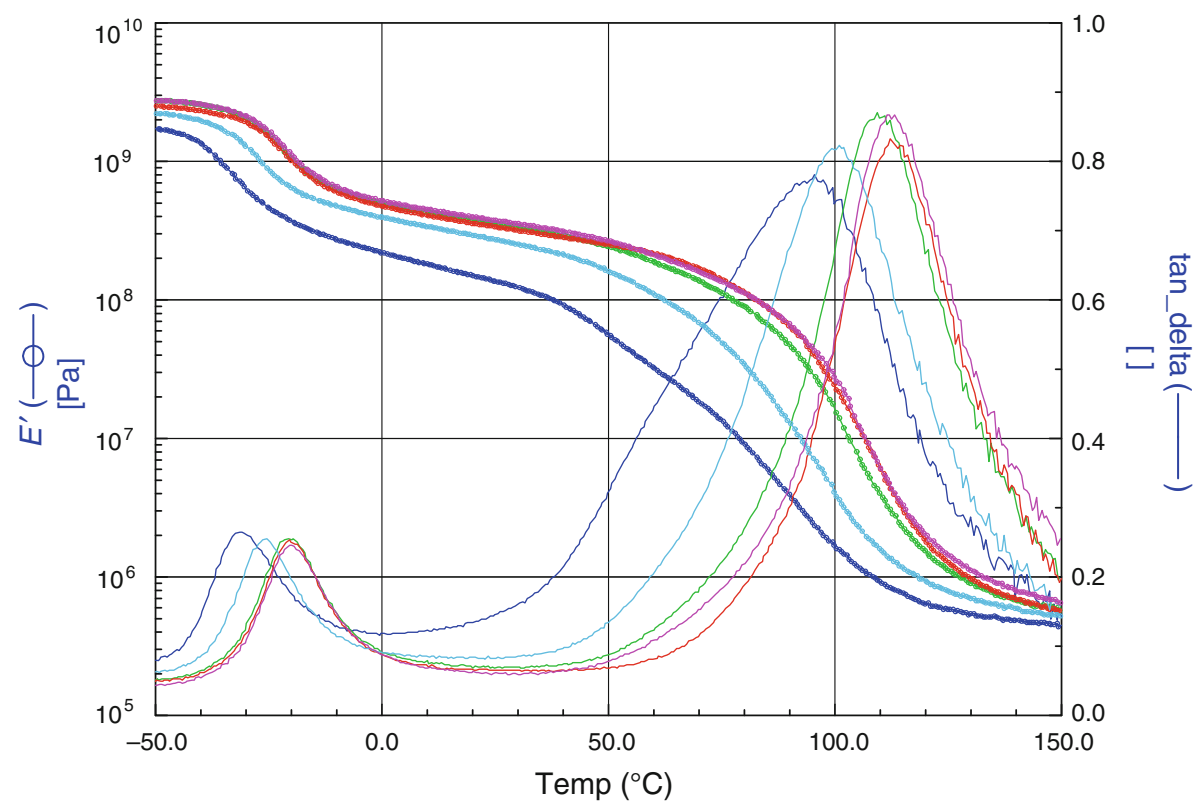

Fig. 5: $E^{\prime}$-modulus- and tan delta-curves of the binder after different periods of drying time by the addition of 3 wt $\%$ BDG. Blue lines: after 3 days RT, light blue lines: after 10 days RT, green lines: after 4 weeks RT, violet lines: after 11 weeks RT, red lines: after 3 days $\mathrm{RT}+11$ days at $40^{\circ} \mathrm{C}$ (Color figure online)

However, after 10 days of drying the peak maxima of the tan delta-curve are located at slightly higher temperatures: the soft phase shows a further shift to higher temperatures, whereas the shoulder for the hard phase is much less pronounced. This leads to a higher $E^{\prime}$-modulus at intermediate temperatures and has consequences for the performance of the coatingespecially after short drying times. For example, if the $E^{\prime}$-modulus at $50^{\circ} \mathrm{C}$ is taken as an indication of the blocking resistance performance, BDG will be less effective in obtaining early hot blocking resistance as opposed to Texanol or water after 3 days drying. After 
11 weeks of drying at RT the DMTA-curve is almost identical to the DMTA-curve after drying for 1 week at $40^{\circ} \mathrm{C}$ : the hard phase hardly contains any residual BDG.

In Fig. 6, the effect of $3 \mathrm{wt} \%$ addition of Solvenon DPM is shown. This solvent exhibits a strong effect at especially the hard phase, when compared to BDG. Drying of the film is also very fast when compared to BDG: after 4 weeks of drying at RT, the final result is already provided.

In Figs. 7, 8, and 9 the effects of the three solvents on the dynamic mechanical behavior during drying after $3,10 / 11$, and 28/49 days RT is compared to drying of the film made from the pure dispersion. It is very clear that BDG after 3 days drying has the greatest effect especially on the position of the hard phase glass transition, but after 10/11 days Texanol is more present in the film. In the end, the film formulated with BDG reaches the highest modulus values between both glass transitions. The reason will be, that with this solvent in the beginning the glass transition of the hard phase was most strongly influenced, resulting in the highest mobility of the polymeric system as a whole. This in its turn results in the best annealing effect of nonthermodynamically stable structures and domains in the film. In the end, phase separation of hard and soft phases will be optimal for this solvent.

From an application point of view, the early blushing resistance as well as the early hot blocking resistance are greatly dependent on the type of coalescent used (Figs. 10, 11). Here films were cast of ca. $100 \mu \mathrm{m}$ dry thickness und using 1, 2, and $3 \mathrm{wt} \%$ of coalescent on binder only. The early water resistance of the films cast with Texanol is remarkably good, which is probably due to the fact that the residual coalescent either hampers the penetration of water into the film (due to the enhanced hydrophobicity by Texanol's presence) or distributes it in such a way that no "water pockets" that scatter the light are created. BDG and DPM at $1 \mathrm{wt} \%$ lead to relatively strong blushing, but 2 and $3 \mathrm{wt} \%$ give better results. This could be due to the fact that the $T_{\mathrm{g}}$ of the hard phase is not sufficiently suppressed by the small amount of coalescent (and hence incomplete film formation of the hard phase has taken place) or residual hydrophilic solvent facilitates faster water-uptake or both. Nevertheless, drying for 1 week shows that higher amounts of BDG and DPM give excellent blushing resistance, and Texanol shows stronger blushing at all concentrations. It can be safely assumed that after 7 days drying the coalescent at all concentrations has fully evaporated from $100 \mu \mathrm{m}$ thick films. The results can then be explained by considering the effect on film formation of the hard phase (compare also with Figs. 4, 5, 6). Lower amounts of both hydrophilic coalescents $(1 \mathrm{wt} \%)$ apparently do not plasticize the hard phase sufficiently to get the desired film formation and interpenetration of the polymer chains. BDG is in this case more effective than DPM, as at $2 \mathrm{wt} \%$ it enables excellent blushing resistance after $4 \mathrm{~h}$, whereas DPM starts to show some blushing. Since Texanol does not partition as strongly in the hard phase, it does not contribute sufficiently to its film formation and henceforth strong blushing can be seen after 1 week drying.

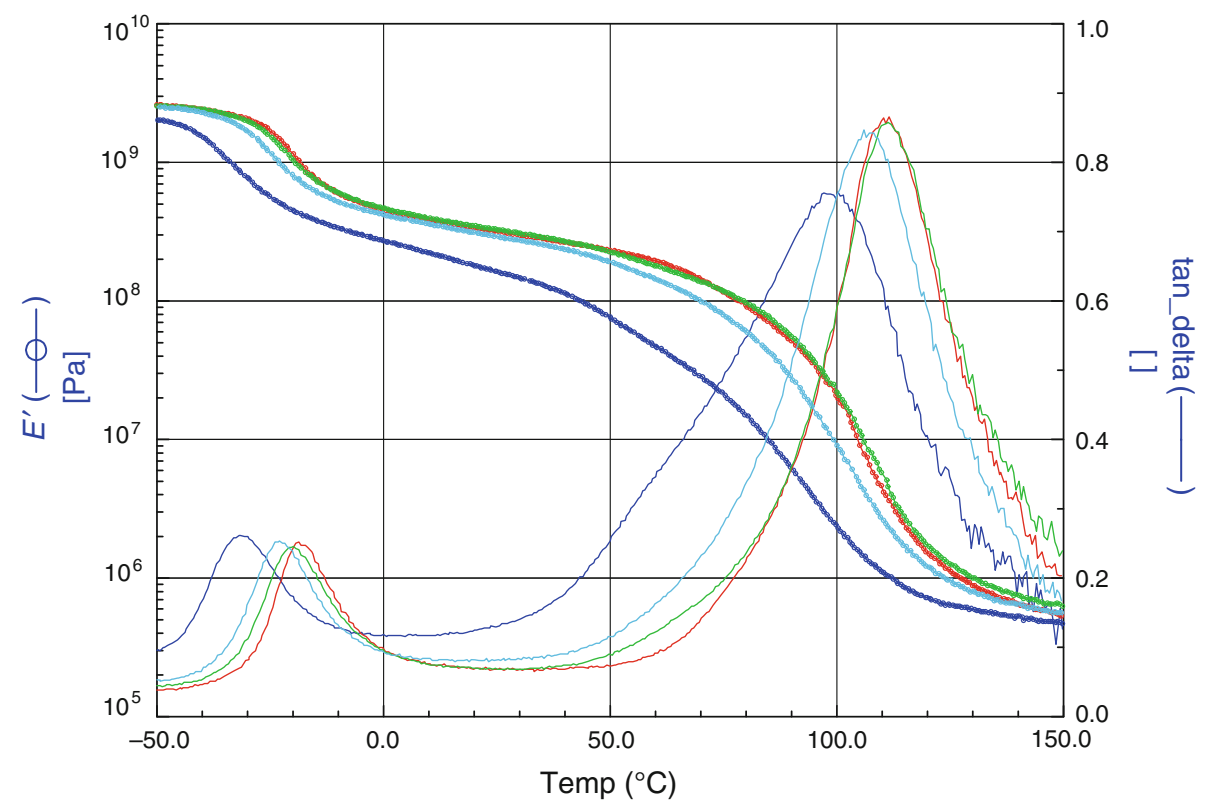

Fig. 6: $E^{\prime}$-modulus- and tan delta-curves of the binder after different periods of drying time by the addition of 3 wt $\%$ Solvenon DPM. Blue lines: after 3 days RT, light blue lines: after 10 days RT, green lines: after 4 weeks RT, red lines: after 13 days $\mathrm{RT}+6$ days at $40^{\circ} \mathrm{C}$ (Color figure online) 


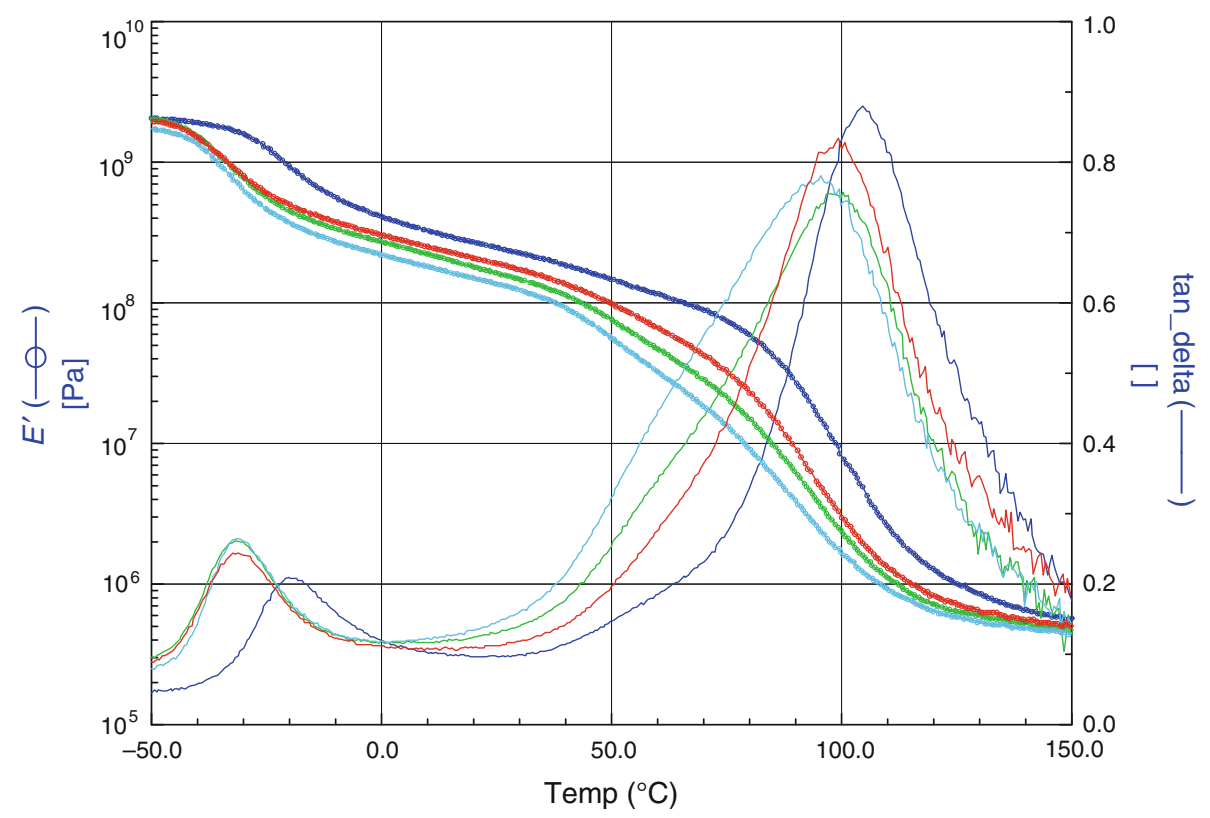

Fig. 7: $E^{\prime}$-modulus- and tan delta-curves of the binder after 3 days RT drying. Blue lines: as such, light blue lines: BDG, green lines: Solvenon DPM, red lines: Texanol (Color figure online)



Fig. 8: $E^{\prime}$-modulus- and tan delta-curves of the binder after 10/11 days RT drying. Blue lines: as such, light blue lines: BDG, green lines: Solvenon DPM, red lines: Texanol (Color figure online)

On the other hand, the early hot blocking resistance shows that Texanol performs extremely well (Fig. 11, $24 \mathrm{~h}$ drying), whereas both DPM and BDG perform worse, especially at higher amounts. The previously presented DMTA-curves in Figs. 7, 8, and 9 again reveal an explanation: the stronger partitioning of these hydrophilic coalescents in the hard phase as well as their apparent slow evaporation prevent the required built-up of the hard phase to participate meaningfully in providing sufficient blocking resistance. Texanol does not partition as strongly in the hard phase and at low amounts is sufficiently removed from the hard phase to give good hot blocking resistance. Nevertheless, after prolonged periods of 


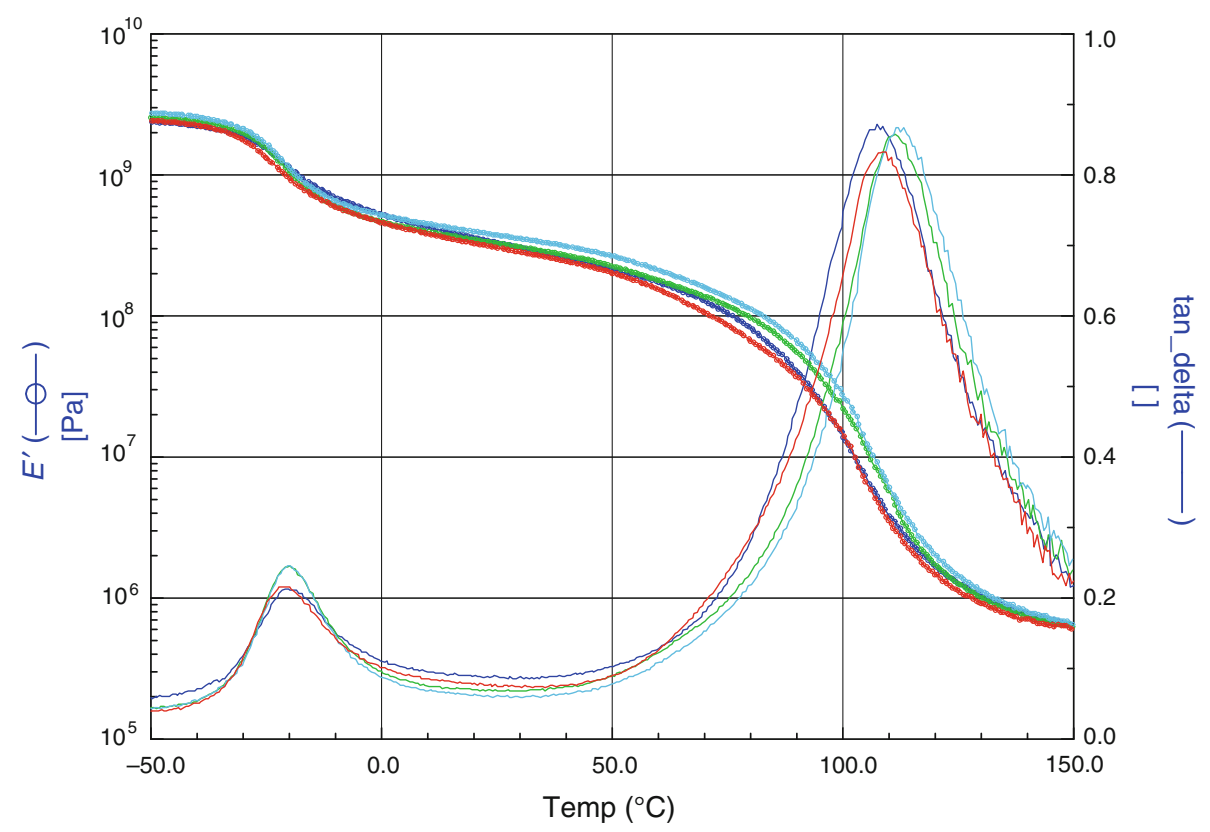

Fig. 9: $E^{\prime}$-modulus- and tan delta-curves of the binder after 49 days RT drying. Blue lines: as such, light blue lines: BDG, green lines: Solvenon DPM (after 4 weeks), red lines: Texanol (Color figure online)

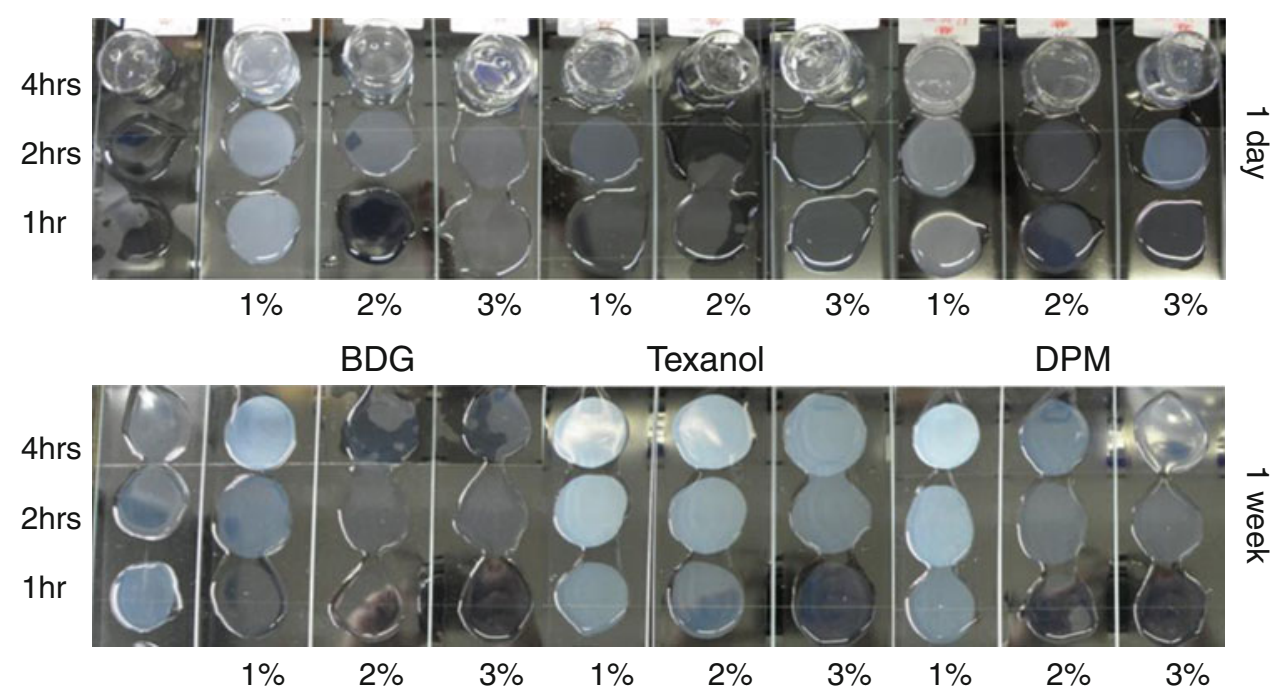

Fig. 10: Blushing resistance of $100 \mu \mathrm{m}$ thick films on glass over a black background cast with different amounts of coalescents after 1 day (top) or 7 days (bottom) drying at water contact times of 1 , 2, and $4 \mathrm{~h}$

drying (Fig. 11, 7 days drying) DPM shows good hot blocking resistance on par with Texanol, at $3 \mathrm{wt} \%$ even slightly better due to better film formation of the hard phase. The same is true for higher amounts of BDG. Again, the DMTA-curves in Figs. 7, 8, and 9 nicely corroborate these findings.

So, if a good balance between early hot blocking resistance and early blushing resistance is required, a combination of a hydrophilic and a hydrophobic coalescent will lead to the best compromise for this type of multiphase acrylic binder. The hydrophobic and the hydrophilic coalescent will partition differently over the hard and soft phase as well as the aqueous phase. Of course, the hydrophilic coalescent will also influence the partitioning of the hydrophobic coalescent (and vice versa) over these different phases, so this does require some fine-tuning on the formulators side. The result might be that less coalescent may be needed to get better performance.

The effect of other additives, e.g., thickeners, light stabilizers, and matting agents that eventually go into a high-end wood coating has not been investigated, but 


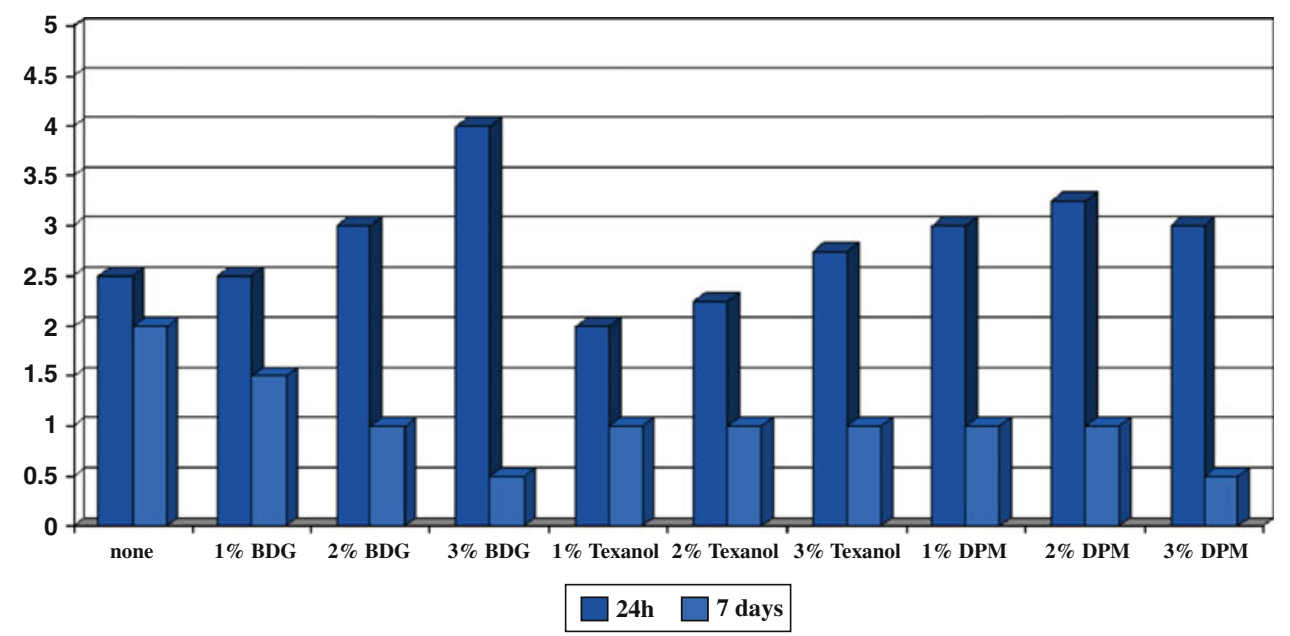

Fig. 11: Scores as a function of coalescent amount measuring the hot blocking resistance after $24 \mathrm{~h}$ and 7 days drying at room temperature, followed by blocking at $50^{\circ} \mathrm{C}$ for $24 \mathrm{~h}$ with $400 \mathrm{~g} / \mathrm{cm}^{2}$. A 0 indicates perfect blocking resistance (the panels fell apart) and a 5 corresponds to bad blocking behavior (the panels could not be separated)

can be expected to also play a large role on the overall performance of the wood coating.

\section{Conclusions}

We systematically studied the effect of three commonly used coalescents (BDG, DPM, and Texanol) upon film formation of core-shell dispersions, where the shell consists of a hydrophilic hard polymer phase. Hydroplasticization of the hard phase reduces the $T_{\mathrm{g}}$ of this hard phase from 84 to $55^{\circ} \mathrm{C}$ as shown by aqueous DSC-measurements. In the original latex BDG and DPM are primarily located in the aqueous phase as opposed to Texanol, but during the drying BDG and DPM are more effective at reducing the MFFT of the hard phase. Due to the evaporation of the aqueous phase these coalescents partition stronger into the hydrophilic hard phase of the polymer and aid in its film formation. This was further corroborated by DMTA-measurements after different time intervals during the film formation process: the three different coalescents lead to quite different plasticization of the hard and soft phase. Texanol remains more strongly present in the soft phase polymer, whereas DPM partitions more strongly towards the hard phase. BDG is somewhat in the middle. This partitioning of the coalescent between the phases during the drying process has an enormous effect on the overall performance of the binder, especially during its early service life, but also when the film formation process is completed due to the postfilm formation crosslinking. The early blushing resistance and the early hot blocking resistance with Texanol are better than with BDG and DPM. However, DPM and especially BDG show excellent hot blocking and blushing resistance after these coalescents have left the film-the performance of the binder lies on a higher level than can be obtained by Texanol. This can once again be explained by the partitioning of the coalescent over the hard, the soft and the aqueous phases during the complete drying process. So, the binder's performance is strongly dependent on the drying time and the type of coalescent under use. It is clear that depending on the desired application profile of the coating coalescent mixtures may bring advantages, especially in the early performance of the binder.

Acknowledgments The authors wish to thank the management of BASF SE for granting publication of this manuscript and Anna-Elisabeth Nick, Günther Ulpins, Stefan Lichtmannegger, Sebastian Schmitz, and Annika Landes for their synthetic and analytical support. Rudiger Stark is acknowledged for AFMimaging.

Open Access This article is distributed under the terms of the Creative Commons Attribution License which permits any use, distribution, and reproduction in any medium, provided the original author(s) and the source are credited.

\section{References}

1. Bullian, F, Graystone, J, Wood Coatings: Theory and Practice, pp. 1-315, Elsevier, Amsterdam, 2009

2. Eckersley, ST, Rudin, A, "Film Formation of Acrylic Copolymer Latices: A Model of Stage II Film Formation." ACS Symp. Ser., 694 2-21 (1996)

3. Dobler, F, Holl, Y, "Mechanisms of Particle Deformation During Latex Film Formation." ACS Symp. Ser., 694 22-43 (1996)

4. Holl, Y, Keddie, JL, McDonald, PJ, Winnik, MA, "Drying Modes of Polymer Colloids." ACS Symp. Ser., 790 2-26 (2001)

5. Brun, A, Dihang, H, Brunel, L, "Film Formation of Coatings Studied by Diffusing-Wave Spectroscopy." Prog. Org. Coat., 61 181-191 (2008) 
6. Ciampi, E, Goerke, U, Keddie, JL, McDonald, PJ, "Lateral Transport of Water During Drying of Alkyd Emulsions." Langmuir, 16 1057-1065 (2000)

7. Wang, Y, Winnik, MA, Haley, F, "Latex Film Formation at the Molecular Level: The Effect of Coalescing Aids on Polymer Diffusion." J. Coat. Technol., 811 (64) 51-60 (1990)

8. Turshatov, A, Adams, J, Johannsmann, D, "Interparticle Contact in Drying Polymer Dispersions Probed by TimeResolved Fluorescence." Macromolecules, 41 5365-5372 (2008)

9. Ming, Y, Takamura, K, Davis, HT, Scriven, LE, "Microstructure Evolution in Latex Coatings." TAPPI J., 78 151-159 (1995)

10. Rieger, J, Hädicke, E, Ley, G, Lindner, P, “Crystals Made of Close-Packed Polymeric Spheres: A Neutron Scattering Study on Latex Films." Phys. Rev. Lett., 68 2782-2785 (1992)

11. Bieleman, J, Additives for Coatings, pp. 180-200. WileyVCH Verlag GmbH, Weinheim, 2001

12. Overbeek, A, "Polymer heterogeneity in waterborne coatings." J. Coat. Technol. Res., 7 1-21 (2010)

13. Fu, Z, Hejl, A, Swartz, A, "Designed Diffusion Technology: A Paradigm Shift in Film Formation." Eur. Coat. J., 6 26-33 (2009)

14. Sperry, PR, Snyder, BS, O'Dowd, ML, Lesko, PM, "Role of Water in Particle Deformation and Compaction in Latex Film Formation." Langmuir, 10 2619-2628 (1994)
15. Lee, DI, Walker, LC, Kann, CS, “The Thermal Behavior of Latexes: Wet Latex Glass Transition Temperatures." Macromol. Symp., 118 267-273 (1997)

16. Tsavalas, JG, Sundberg, DC, "Hydroplasticization of Polymers-Model Predictions and Application to Emulsion Polymers.” Langmuir, 26 6960-6966 (2010)

17. Taylor, JW, Klots, TD, "Applied Approach to Film Formation." Eur. Coat. J., 6 38-54 (2002)

18. Schuler, B, Baumstark, R, Kirsch, S, Pfau, A, Sandor, M, Zosel, A, "Structure and Properties of Multiphase Particles and Their Impact on the Performance of Architectural Coatings." Prog. Org. Coat., 40 139-150 (2000)

19. Lee, S, Rudin, A, "Control of Core-Shell Latex Morphology." ACS Symp. Ser., 492 234-254 (1992)

20. Baah, F, Berkhout, L, "Performance of a New Generation Self-Crosslinking Polymers for Joinery Application." Eur. Coat. J., 3 102-107 (2005)

21. Baah, F, Berkhout, L, "New Waterborne Self-Crosslinking Polymers for Joinery Applications." Surf. Coat. Int. Part A, 89 384-390 (2006)

22. Stratta, JJ, Dillon, PW, Semp, RH, "Evaporation of Organic Cosolvents from Water-Borne Formulations." J. Coat. Technol., 50 (647) 40-47 (1978)

23. Holten-Anderson, J, Hansen, CM, "Solvent and Water Evaporation from Coatings." Prog. Org. Coat., 11 219-2140 (1983)

24. http://www.chem.unep.ch/irptc/sids/oecdsids/25265774.pdf. 